\title{
ONLINE FEEDBACK IMPACT ONLINE SHOPPERS' IMPULSE PURCHASES IN MALAYSIA
}

\author{
Lu Man Hong ${ }^{1 *}$, Wan Farha Wan Zulkiffli ${ }^{2}$, Che Adawiah Che Amran ${ }^{3}$ \\ 1,2,3 Faculty of Business and Entrepreneurship, Universiti Malaysia Kelantan, Malaysia \\ Email: ${ }^{1}$ vicklumanhong@gmail.com; ${ }^{2}$ farha@umk.edu.my; ${ }^{3}$ achecheq@gmail.com \\ *Corresponding author
}

\begin{abstract}
Online shopping had risen to the third position among Malaysians who used the Internet. Typically, past customer online reviews were deciding factors for an online business's success or failure because online consumers encountered online reviews while visiting a website, and it was a direct effect on their ability to purchase impulsively and online impulse buying conduct. The majority of previous research on market-generated context as a factor in online impulse buying behavior had concentrated on the market-generated background. As a result, this research identified two types of online reviews as independent variables, namely hedonic and utilitarian value online reviews, and browsing and the willingness to buy impulsively as intervening and moderating variables respectively. While online impulse buying behavior was the dependent variable. This study only involved online shoppers who had made at least one purchase on both Lazada Malaysia and Shopee Malaysia websites. This study took a quantitative approach, with 100 responses collected from online shoppers who had made at least one purchase on Shopee Malaysia and Lazada Malaysia through an online questionnaire. Due to the deletion of one straight-lining response, 99 responses were subjected to data analysis using SmartPLS software. Hedonic value online reviews influence browsing, and browsing influences urged to buy impulsively and directly to online impulse purchasing, according to the results.
\end{abstract}

Keywords: Browsing, hedonic value online review, online impulse buying behavior, utilitarian value online review, urge to buy impulsively.

\section{Introduction}

Technology advances have made it easier for people to complete tasks in their daily lives. This included the fact that year after year, shopping practices are becoming more convenient. According to a CIA survey in 2009, 15 million Malaysians used the internet in 2009, rising to 17 million in 2012 (International Telecommunication Union, 2012). As the country's internet use increased, the Malaysian ecommerce industry gained a lot of information. Despite the many advantages of shopping online, consumers are hesitant to do so. As a result, consumers are more likely to look for previous consumer reviews of products and services, as well as retailers, while visiting a website to make purchasing decisions (Reimer \& Benkenstein, 2016; Yang, Sarathy, \& Lee, 2016).

In most previous online impulse purchasing behavior research, user factors such as website design and product characteristics became attractive focus variables (Lo, Lin, \& Hsu, 2016; Rezaei, Ali, Amin, \& Jayashree, 2016). Furthermore, empirical research (Zhang, Xu, Zhao, \& Yu, 2018) reveals that there are few studies on the social effect on online purchasing behavior, especially in Malaysia. This research builds on the results of Zhang et al. (2018), which looked at the relationship between online reviews and browsing, then browsing and the desire to buy impulsively, and finally the desire to buy impulsively and online impulse buying behavior. Furthermore, this study only looks at customers who shop on Lazada Malaysia and Shopee Malaysia according to an Asean Up report from 2019, Lazada Malaysia and Shopee Malaysia are ranked first and second in monthly traffic estimates among Malaysian e-commerce websites. Therefore, this study is to identify online review towards browsing, browsing towards urge to buy impulsively then urge to buy impulsiveness towards online impulse buying behavior based on Lazada and Shopee online shoppers in Malaysia. Furthermore, this study is to identify the moderating effect of impulsiveness between the relationship of the urge to buy impulsiveness and online impulse buying behavior.

\section{Online Impulse Buying Behavior}

There are four types of impulse purchases according to Chen and $\mathrm{Ku}$ (2021): pure, reminder, suggestion, and planned. "Individuals becoming erratic in their daily shopping patterns, resulting in impulse buying behavior" as reviewed by (Chen \& Ku, 2021). 
Reminder impulse buying is described as a person's out-of-the-ordinary purchasing behaviors that combine experience or product knowledge with cognitive effort (Zhang et al., 2018). The phenomenon of suggestion impulse buying occurs when people are drawn to new products (Chen \& Ku, 2021; Zhang et al., 2018). Individuals indulge in calculated impulse buying by seeking out exclusive offers to purchase items that will satisfy their desires (Chen \& Ku, 2021; Zhang et al., 2018).

Zhang et al. (2018) found that the appended relational process has a greater effect on individuals' suggestion impulse buying and pure impulse buying than the emotional reaction. As a result, online impulse buying behavior is described in this study as online consumers' pursuit of products or services within a shopping objective and an advanced arrangement that is influenced by online research, knowledge screening, and search activities (Zhang et al., 2018).

\section{Online Review}

Online reviews as compared to marketer-generated content such as commercials and sellers' product descriptions, are more persuasive to consumers and are similar to electronic word of mouth (eWOM) (Hussain et al., 2018). Consumers tend to read online feedback from former customers because it decreases their uncertainty, saves time searching for a good product, alleviates their dissatisfaction, and expands their opportunities to learn about new products (Hussain $e t$ al., 2018). Indeed, a previous customer's recommendation improves trust, purchasing intent, risk avoidance, and profits (Ladhari \& Michaud, 2015; Matute, PoloRedondo, \& Utrillas, 2016).

Online reviews have the potential to engage a vast number of people all over the Internet, making them valuable marketing tools for retailers (Baber et al., 2016). Since neither practical nor negative reviews from previous customers about products or sellers affect whether or not online consumers buy, the effect of variation on product ratings has a significant impact on their purchasing decision (Engler, Winter, \& Schulz, 2015). Consumers may find relevant online feedback to help them meet their online shopping goals, which are split into two categories: practical and hedonic (Zhang et al., 2018).

\section{Utilitarian Value Online Review}

Zhang et al. (2018) describe utilitarian value as a task-specific value of shopping that reflects the efficient purchasing of products, while hedonic value is a positive feeling associated with shopping. Thus, utilitarian value online review justifies as the perception of online review capable of providing significant value for online consumers to satisfy their desires (Zhang et al., 2018). According to Zhang et al. (2018) and Chen and $\mathrm{Ku}$ (2021), utilitarian value is a task-specific value of shopping that represents productive product buying.

The quality of an online review can persuade a customer to make an online purchase (Maslowska, Malthouse, \& Bernritter, 2017). Consumers perceive appropriate online review based on their shopping priorities based on previous reviews, which may affect their shopping website search and viewing goals. Zhang et al. (2018) justifies that the sources of online review capable to trigger impulsiveness buying. Hence, the hypothesis showed as below:

$H_{l}$ : Utilitarian Value online review positively influences browsing among Malaysian online consumers.

\section{Hedonic Value Online Review}

Hedonic value online review justifies as the perception of online review capable of providing a sense of fulfilment on individuals' feelings for online consumers (Zhang et al., 2018). Besides, hedonic value is a pleasant feeling associated with shopping (Chen \& Ku, 2021).

According to Maslowska et al. (2017), the content of an online review will convince a customer to make an online purchase. Consumers perceive relevant online feedback based on their shopping priorities based on previous reviews, which can influence their search and viewing goals on shopping websites.

$\mathrm{H}_{2}$ : Hedonic Value online review positively influences browsing among Malaysian online consumers.

\section{Browsing}

Customers can spend time searching online shops (Badgaiyan \& Verma, 2015). As a consequence, when visiting a particular shopping website, online reviews have become important determinants of online impulse buying behavior (Zhang et al., 2018). This is because, while browsing a website, consumers may perceive online reviews as triggering their product needs rather than their shopping goals (Zhang et al., 2018). As a result, browsing is defined as an ideal way for Lazada Malaysia online shoppers to search for and screen information related to a specific shopping goal in this report (Zhang et al., 2018). 
According to a study by Xi et al. (2016), browsing the online context shared by previous customers in social media networks can significantly influence consumers' impulse buying. This can be explained by the fact that, as a result of the increase in social media use, individual buying behavior, includeing impulse purchases, can be affected by social influence (Aragoncillo \& Orus, 2018).

Browsing may justify consumers' in-progress diversion to search and screen on certain online shopping websites (Zhang et al., 2018). Furthermore, browsing is an unintended, warped, and driven presearch process (Zhang et al., 2018). Customers may feel compelled to buy something impulsively while browsing a shopping website that takes up their time. As a result, the following is the hypothesis:

$H_{3}$ : Browsing positively influence the urge to buy impulsively among Malaysian online consumers.

\section{Urge to Buy Impulsively}

According to Kazempour and Lotfizadeh (2017), during online shopping, individuals experience a sense of nothing being simple, immediate, or enjoyable at the same time, without any logic or consequences. In other words, an impulse to buy impulsively is a substantial and intense desire to buy impulsively for people who do not want to buy online (Kazempour \& Lotfizadeh, 2017). As a result, impulsive buying is described as an online shopper's sudden or spontaneous urge to purchase goods or services from a website (Zhang et al., 2018).

The tendency to buy impulsively is caused by short -lived moments and is related to other urges like curiosity and novelty change (Kazempour \& Lotfizadeh, 2017). To put it another way, the willingness of consumers to buy products encourages impulsive purchases (Kazempour \& Lotfizadeh, 2017). Consider how consumers develop short-term interest as a result of online feedback, which significantly increases the temptation to buy impulsively and contributes to online impulse shopping. As a result, the following is the hypothesis:

$H_{4}$ : Urge to buy impulsively positively influence impulse buying behavior among Malaysian online consumers.

\section{Impulsiveness}

Impulsiveness has been described as "both propensities based on experiences spontaneous and unpredictable impulses to make on-the-spot purchases and it also to act on these felt urges with little deliberation or consequences evaluation" (Zhang et al., 2018). As a consequence, impulsivity tends to be related to a stable personality trait (Wadera \& Sharma, 2018). To combat this, impulsiveness was used in this study to explain a one-of-a-kind strategy for online shoppers who purchase products or services on the spur of the moment (Zhang et al, 2018).

Individuals can hold opposing views on the degree of impulsivity (Zhang et al., 2018; Chen \& Ku, 2021). As a consequence, impulsiveness affects consumers' intentions to shop online (Zhang, Prybutok, \& Koh, 2006), as high impulsiveness consumers are more likely than low impulsiveness consumers to lack self -control in an online store environment (Zhang et al., 2018). Furthermore, impulsivity has the power to sway people's natural judgement and willingness to buy on the spur of the moment (Zhang et al., 2018). As a consequence, in this research, impulsivity can be considered a moderator, with the following hypothesis:

$H_{5}$ : The relationship between browsing and urge to buy impulsively will positively be moderated by impulsiveness among Malaysian online consumers.

\section{Research Framework}

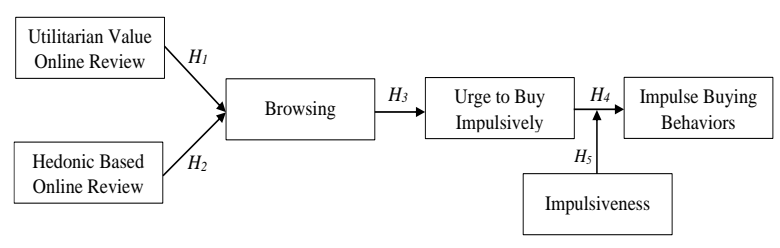

Figure 1. Research framework

\section{Research Method}

Since this study used numeric analysis, the quantitative methodology used in this study can be justified. The study's participants, according to an Asean Up report from 2019, are online shoppers who have made at least one purchase on Lazada Malaysia and Shopee Malaysia, which are ranked first and second in monthly traffic estimates among Malaysian e-commerce websites. According to Hair Jr, Hult, Ringle, and Sarstedt (2016), the sample size in SmartPLS can be determined by 10 times the number of structural paths in the structural model that are guided at a single build. This study consists of six paths which indicated that 60 responses as a fair number sample size in this study. In this study, all respondents were chosen using a nonrandom convenience sampling process, and 100 responses were collected using an online questionnaire. Only 99 responses were analysed using SPSS and SmartPLS software since one response was given a straight-lining answer form. 
In addition, the study employed a seven-point Likert scale since Finstad (2010) contrasted the 5-point and 7-point Likert Scales, concluding that the 5-point Likert Scale was unable to reliably collect data and was insensitive enough to record true robustness in respondents' device evaluations. Frequency analysis was used as a function in the statistical analysis method to summarise the demographic profile in table form using SPSS software. Measurement model analysis and SmartPLS path coefficient are the two phases of the SmartPLS programme. The path coefficient tests whether the hypotheses in this study were approved or rejected, and the primary roles of measurement model analysis in describing the construct are reliability and validity.

\section{Findings and Discussion}

Frequency Analysis

Table 1

Summary of Demographic Profile for Online Consumers

\begin{tabular}{|c|c|c|}
\hline Descriptions & Frequency & Percentage \\
\hline \multicolumn{3}{|l|}{ Gender } \\
\hline$\overline{\text { Male }}$ & 37 & 37.40 \\
\hline Female & 42 & 49.50 \\
\hline \multicolumn{3}{|l|}{ Race } \\
\hline$\overline{\text { Malay }}$ & 79 & 79.80 \\
\hline Chinese & 15 & 15.20 \\
\hline Indian & 4 & 4.00 \\
\hline Others & 1 & 1.00 \\
\hline \multicolumn{3}{|l|}{ Age } \\
\hline 20 years old and below & 8 & 8.10 \\
\hline 21-25 years old & 37 & 37.40 \\
\hline 26-30 years old & 33 & 33.30 \\
\hline 31-35 years old & 10 & 10.10 \\
\hline $36-40$ years old & 7 & 7.10 \\
\hline 41-50 years old & 4 & 4.00 \\
\hline \multicolumn{3}{|l|}{ Education } \\
\hline SPM & 5 & 5.10 \\
\hline STPM & 9 & 9.10 \\
\hline Diploma & 14 & 14.10 \\
\hline Degree & 51 & 51.50 \\
\hline Master & 13 & 13.10 \\
\hline $\mathrm{PhD}$ & 6 & 6.10 \\
\hline Others & 1 & 1.00 \\
\hline \multicolumn{3}{|l|}{ Occupation } \\
\hline$\overline{\text { Government }}$ & 15 & 15.20 \\
\hline Private & 27 & 27.30 \\
\hline Self-employed & 21 & 21.20 \\
\hline Students & 25 & 25.30 \\
\hline Unemployed & 11 & 11.10 \\
\hline \multicolumn{3}{|l|}{ Time Spent } \\
\hline$\overline{\text { Less than } 10}$ minutes & 7 & 7.10 \\
\hline \multicolumn{3}{|l|}{$10-30$ minutes } \\
\hline $31-60$ minutes & 39 & 39.40 \\
\hline $1-2$ hours & 18 & 18.20 \\
\hline 3-5 hours & 20 & 2.20 \\
\hline 5-7 hours & 8 & 8.10 \\
\hline \multirow[t]{2}{*}{ More than 7 hours } & 1 & 1.00 \\
\hline & 2 & 6.10 \\
\hline
\end{tabular}

The demographic profile of the respondents in this study is summarised in Table 1, which shows that the majority of respondents are Malay women aged 21 to 25 who are active shoppers. In terms of education, the majority of respondents have a Bachelor's degree, with a Diploma coming in second. Furthermore, 25 of the respondents are students and 27 are private-sector staff. Finally, the majority of people are likely to have spent between 10 and 30 minutes shopping online.

\section{Measurement Model Analaysis}

Table 2

Measurement Model Result

\begin{tabular}{llccc}
\hline Constructs & Item & Loading & CR & AVE \\
\hline Utilitarian value & UV 1 & 0.85 & & \\
& UV 2 & 0.90 & 0.93 & 0.81 \\
UV 3 & 0.94 & & \\
Hedonic value & HV 1 & 0.75 & & \\
& HV 2 & 0.87 & 0.90 & 0.69 \\
& HV 3 & 0.88 & & \\
Browsing & HV 4 & 0.81 & & \\
& Brow 1 & 0.88 & 0.90 & 0.71 \\
Urge to Buy & Brow 2 & 0.80 & & \\
Impulsively & Urge 1 & 0.93 & & \multirow{2}{*}{0.82} \\
& Urge 2 & 0.90 & 0.93 & \\
Impulsiveness & Urge 3 & 0.88 & & \\
& Impulse1 & 0.88 & & \\
& Impulse2 & 0.90 & 0.94 & 0.800 \\
Impulse Buying & Impulse3 & 0.90 & & \\
Behaviors & IBB & 1.00 & 1.00 & 1.00 \\
\hline
\end{tabular}

Table 2 shows the results of the measurement model analysis in this study. Every build's factor loading varies from 0.75 to 1.00 , meeting Hair $\mathrm{Jr}$ et al. (2016)'s requirement that the factor loading is greater than 0.71. Furthermore, the composite reliability (CR) value for each construct in this study ranges from 0.90 to 1.00 , meeting Hair Jr et al. (2016)'s CR value criterion of greater than 0.70 . Furthermore, in this analysis, the Average Variance Extracted (AVE) varies from 0.69 to 1.00, fulfilling Hair Jr et al. (2016)'s criterion of AVE being greater than 0.50 . To summarise, all of the constructs in this analysis are accurate and reliable.

\section{Discriminant Validity}

Table 3

Discriminant Validity of Constructs (Stringent Criterion)

\begin{tabular}{lcccccc}
\hline & Brow & HV & Impusle & IBB & Urge & UV \\
\hline Brow & & & & & & \\
HV & 0.81 & & & & & \\
Impulse & 0.56 & 0.31 & & & & \\
IBB & 0.61 & 0.34 & 0.77 & & & \\
Urge & 0.79 & 0.51 & 0.73 & 0.54 & & \\
UV & 0.46 & 0.72 & 0.07 & 0.16 & 0.28 & \\
\hline
\end{tabular}

Note: Brow: Browsing; HV: Hedonic value; Impulse: Impulsiveness; IBB: Impulse buying behavior; Urge: Urge to Buy Impulsively; UV: Utilitarian Value 
Table 3 indicates the discriminant validity results in this study. According to Hair Jr et al. (2016), the main function of discriminant validity is to define the multicollinearity problem among constructs in this study, and the Stringent criterion justifies a value of less than 0.85 . As a consequence, since all of the structures in this study have values less than 0.85 , they have fewer multicollinearity issues.

\section{Path Coefficient}

Table 4

The Path Coefficient Result

\begin{tabular}{lccccc}
\hline & $\begin{array}{c}\text { Direct } \\
\text { Effect }\end{array}$ & $\begin{array}{c}\text { Standard } \\
\text { Error }\end{array}$ & t-value & p-value & Sig. \\
\hline$H_{1}$ & -0.02 & 0.09 & 0.23 & 0.41 & No \\
$H_{2}$ & 0.60 & 0.09 & 6.45 & 0.00 & Yes \\
$H_{3}$ & 0.28 & 0.09 & 2.99 & 0.00 & Yes \\
$H_{4}$ & 0.52 & 0.09 & 6.26 & 0.00 & Yes \\
\hline
\end{tabular}

Note: Brow: Browsing; HV: Hedonic value; Impulse: Impulsiveness; IBB: Impulse buying behavior; Urge: Urge to Buy Impulsively; UV: Utilitarian Value

Hypotheses 2, 3, and 4 are accepted in this study, according to Hair Jr et al. (2016), since the p-value is less than 0.05 and the $t$-value is greater than 1.65 if the hypothesis is based on a directional hypothesis. As a result, hedonic value online reviews are positively associated with browsing, browsing is positively associated with the desire to purchase impulsively, and the desire to buy impulsively is positively associated with online impulse buying conduct.

\section{The Moderating Effect}

Table 5

The Moderating Testing Result

\begin{tabular}{ccccc}
\hline & Std. Beta & Std. Error & t-value & Decision \\
\hline$H_{5}$ & -0.05 & 0.04 & 1.39 & Rejected \\
\hline
\end{tabular}

Note: Brow: Browsing; HV: Hedonic value; Impulse: Impulsiveness; IBB: Impulse buying behavior; Urge: Urge to Buy Impulsively; UV: Utilitarian Value

Table 5 shows the results of the moderating effect of impulsiveness in this study. Since the t-value is 1.39, impulsiveness does not moderate the relationship between browsing and the ability to buy impulsively. According to Hair et al. (2016), the appended moderating hypothesis should be defined in the directional hypothesis, and the hypothesis acceptance criterion should be a $t$-value greater than 1.65 .

\section{Discussion}

The findings of this study are useful to a variety of parties, including retailers and marketers, in terms of understanding how online reviews influence online impulse buying behavior on the Lazada and Shopee websites. Surprisingly, utilitarian value online review does not give any credit among target respondents in this study according to the path coefficient result. while browsing website although Zhang et al. (2018) justifies the source of online review capable to trigger impulsiveness buying among China shoppers. This aligned with the study from Chen and $\mathrm{Ku}$ (2021) stated that utilitarian-based consumers willing to spend time to find information to reduce risk uncertainty which significantly reduced the urge to buy impulsively.

On the other hand, hedonic value online reviews have an impact on the target respondents in this study as they visit the website. As a consequence, when reading online feedback on the website, target respondents consider surfing as a leisure activity. This is in line with research by Zhang et al. (2018) and Chen and $\mathrm{Ku}$ (2021), who discovered that online users are more likely to browse a website if it provides a pleasant experience.

Furthermore, the findings revealed that the propensity to purchase impulsively has a positive effect on target respondents' online impulse buying behavior. Zhang et al. (2018) described impulsive buying as a powerful behavior characterised by a strong desire to buy something right away, which is similar to people's online impulse buying behavior. This may explain why target respondents' online impulse purchases were connected to a cause online review they saw while on the web.

Finally, impulsivity has little bearing on the relationship between the hedonic and utilitarian value of online reviews and the desire to purchase on the spur of the moment. According to Aragoncillo and Orus (2018), consumers consider impulsiveness to be higher in offline stores than online stores because the stimulus in online stores usually directly influences consumers' impulse buying. This could explain why the study's target respondents write online reviews, which affect their impulse purchases when they visit the website.

\section{Conclusion}

The goal of this study was to see how utilitarian and hedonic value online feedback influenced browsing, how browsing influenced impulsive buying urges, how impulsive buying urges influenced online impulse buying actions, and how impulsiveness mediated browsing. Surprisingly, the target respondents say that hedonic value online reviews contribute to impulse purchases when they visit the website. Furthermore, their online impulse buying acts are influenced by their 
website surfing. As a result, this can provide convincing proof that the vast majority of Malaysian online customers visit websites for entertainment purposes.

Even though this research provided useful information about the Malaysian e-commerce industry. There are a couple of shortcomings in this study. To begin with, there are only 100 participants in this study who were unable to provide a detailed explanation of how online reviews influence online impulse buying behavior. Furthermore, the study's participants are regular online shoppers who have made at least one purchase on Lazada Malaysia and Shopee Malaysia.

As a result, several research proposals have been made for the future. To begin with, future research should increase the number of responses to obtain more accurate results to better understand the effect of online feedback on online impulse buying behavior. After that, future research might focus on or a specific product sales channel, such as Hermo, a beauty and healthcare website. Finally, different target respondent classes, such as females and males, as well as students, may have varying viewpoints on online reviews and online impulse buying behavior.

\section{References}

Aragoncillo, L., \& Orus, C. (2018). Impulse buying behavior: An online-offline comparative and the impact of social media. Spanish Journal of Marketing-ESIC, 22(1), 42-62. https://doi.org/ 10.1108/SJME-03-2018-007

Baber, A., Thurasamy, R., Malik, M. I., Sadiq, B., Islam, S., \& Sajjad, M. (2016). Online word-ofmouth antecedents, attitude and intention-to-purchase electronic products in Pakistan. Telematics and Informatics, 33, 388-400. http://dx. doi.org/10.1016/j.tele.2015.09.004

Badgaiyan, A. J., \& Verma, A. (2015). Does urge to buy impulsively differ from impulsive buying behavior? Assessing the impact of situational factors. Journal of Retailing and Consumer Services, 22(C), 145-157. https://doi.org/10. 1016/ j.jretcons er.2014.10.002

Chen, C. D., \& Ku, E. C. S. (2021). Diversified online review websites as accelerators for online impulsive buying: The moderating effect of price dispersion. Journal of Internet Commerce, 1-22. https://doi.org/10.1080/15332861.2020. 1868227

Engler, T. H., Winter, P., \& Schulz, M. (2015). Understanding online product ratings: A customer satisfaction model. Journal of Retailing and Consumer Services, 27, 113-120. http://dx.doi. org/10.1016/j.jretconser.2015.07.010.
Finstad, K. (2010). Response interpolation and scale sensitivity: Evidence against 5-point scales. Journal of Usability Studies, 5(3), 104-110.

Hair Jr, J. F., Hult, G. T. M., Ringle, C., \& Sarstedt, M. (2016). A primer on partial least squares structural equation modeling (PLS-SEM). Sage publications.

Hussain, S., Guangju, W., Jafar, R. M. S., Ilyas, Z., Mustafa, G., \& Jianzhou, Y. (2018). Consumers' online information adoption behavior: Motives and antecedents of electronic word of mouth communications. Computers in Human Behavior, 80, 22-32. https://doi.org/10.1016/ j.chb .2017 .09 .019

Kazempour, Y., \& Lotfizadeh, F. (2017). The impact of situational factors (store, personal) on urge to buy impulsively and impulse buying behavior. European Journal of Buisness and Innovation Research, 5(4), 12-27.

Ladhari, R., \& Michaud, M. (2015). eWOM effects on hotel booking intentions, attitudes, trust, and website perceptions. International Journal of Hospitality Management, 46, 36-45.

Lo, L. Y.-S., Lin, S.-W., \& Hsu, L.-Y. (2016). Motivation for online impulse buying: A two-factor theory perspective. International Journal of Information Management, 36(5), 759-772. https://psycnet.apa.org/doi/10.1016/j.ijinfomgt. 2016.04.012

Maslowska, E., Malthouse, E. C., \& Bernritter, S. F. (2017). Too good to be true: The role of online reviews' features in probability to buy. International Journal of Advertising, 36(1), 142-163. https://doi.org/10.1080/02650487.2016.1195622

Matute, J., Polo-Redondo, Y., \& Utrillas, A. (2016). The influence of EWOM characteristics on online repurchase intention: Mediating roles of trust and perceived usefulness. Online Information Review, 40(7), 1090-1110. https://doi.org/ 10.1108/OIR-11-2015-0373

Reimer, T., \& Benkenstein, M. (2016). When good WOM hurts and bad WOM gains: The effect of untrustworthy online reviews. Journal of $\mathrm{Bu}$ siness research, 69(12), 5993-6001. https://doi.org/10.1016/j.jbusres.2016.05.014

Rezaei, S., Ali, F., Amin, M., \& Jayashree, S. (2016). Online impulse buying of tourism products. Journal of Hospitality and Tourism Technology, 7(1), 60-83. http://dx.doi.org/10.1108/JH TT-032015-0018

Wadera, D., \& Sharma, V. (2018). Impulsive buying behavior in online fashion apparel shopping: An investigation of the influence of the internal and external factors among Indian shoppers. South Asian Journal of Management, 25(3), 55-82. 
Xi, H., Hong, Z., Sun, J., Li, X., Wei, J., \& Davison, R. M. (2016). Impulsive purchase behavior in Social Commerce: The role of social influence. Paper presented at the PACIS.

Yang, J., Sarathy, R., \& Lee, J. (2016). The effect of product review balance and volume on online Shoppers' risk perception and purchase intention. Decision Support Systems, 89(C), 66-76. https://doi.org/10.1016/j.dss.2016.06.009.
Zhang, X., Prybutok, V. R., \& Koh, C. E. (2006). The role of impulsiveness in a TAM-based online purchasing behavior. Information Resources Management Journal, 19(2), 54-68. http://dx. doi. org/10.4018/irmj.2006040104.

Zhang, K. Z., Xu, H., Zhao, S., \& Yu, Y. (2018). Online reviews and impulse buying behavior: The role of browsing and impulsiveness. Internet Research, 28(3), 522-543. https://doi.org/10.1 108/IntR-12-2016-0377. 